\title{
Analysis of Antioxidant Activity, Chlorogenic Acid, and Rutin Content of Camellia sinensis Infusions Using Response Surface Methodology Optimization
}

\author{
Magdalena Jeszka-Skowron • Agnieszka Zgoła-Grześkowiak
}

Received: 11 December 2013 / Accepted: 16 March 2014 / Published online: 2 April 2014

(C) The Author(s) 2014. This article is published with open access at Springerlink.com

\begin{abstract}
Optimization of the extraction process of green tea using response surface methodology (RSM) was performed. The optimized conditions were $14.91 \mathrm{~min}$ and $94.15^{\circ} \mathrm{C}(2,2-$ diphenyl-1-picrylhydrazyl (DPPH) assay). The experimental values were close with the predicted values. The procedure was used to measure antioxidant activity using DPPH free radical and phenolic compounds of all types of Camellia sinensis and Tabebuia impetiginosa infusions. The antioxidant activity of infusions was in the order (mean for analyzed types) of pure green tea $>$ white tea $>$ green tea with additives $>$ black tea $=\mathrm{Pu}$-erh tea $>$ semifermented tea $>$ Red Lapacho. After the fermentation process, the content of rutin is lowered and the amount of gallic acid in infusions is increased. A negative correlation between total phenolic acids and organic acids was also observed $\left(R^{2}=0.6437\right)$. Red Lapacho infusion contains phenolic acids such as caffeic, protocatechuic, $p$ coumaric, ferulic, and syringic. No rutin and quercetin were found in this beverage.
\end{abstract}

Keywords DPPH assay · Tea $\cdot$ RSM $\cdot$ Extraction process · Red Lapacho $\cdot$ HPLC/MS/MS

\section{Introduction}

Tea (Camellia sinensis L., family Theaceae), including its black and green varieties, is a product that is used widely throughout the world. Its production and consumption are still

Electronic supplementary material The online version of this article (doi:10.1007/s12161-014-9847-1) contains supplementary material, which is available to authorized users.

M. Jeszka-Skowron $(\varangle) \cdot$ A. Zgoła-Grześkowiak

Institute of Chemistry and Technical Electrochemistry, Poznan

University of Technology, Piotrowo 3, 60-965 Poznan, Poland

e-mail: magdalena.jeszka-skowron@put.poznan.pl on a very high level, and there are predictions that it will be increasing all over the world (FAO 2012). This common beverage is a great source of phenolic compounds such as flavonoids and phenolic acids which are responsible for the total antioxidant activity of tea infusion (Kim et al. 2011). Catechins or flavan-3-ols are the dominant phenolics in green tea leaves and its infusion, but they are frequently determined (Friedman et al. 2005; Horzic et al. 2009; Poon 1998; Rusak et al. 2008; Zimmermann and Gleichenhagen 2011). Other compounds aside from catechins or flavan-3-ols are rarely analyzed in tea, and therefore, it is interesting to determine these compounds in different types of tea available on the market. Tea infusions contain also aglycones and glucosides of flavonols, i.e., quercetin or rutin (5-9\% of all polyphenols and in comparable quantities in all white, green, semifermented, and black tea leaves); phenolic acids such as gallic acid; a group of hydroxybenzoic acids; and chlorogenic acid, caffeic acid, and coumaric acid from the group of hydroxycinnamic acids (Lin et al. 1996, 1998).

Also important to health and for quality of teas are organic acids (Ding et al. 1997; Horie et al. 1998). Organic acids such as succinic acid stimulate the production of adenosine triphosphate, which supplies energy to the cells, stimulate cellular respiration, and act as antioxidants. It is also known that the composition of tea varies with variety, season, age of the leaf, climate, horticultural practices, and technological steps (Kim et al. 2011; Lin et al. 2003). For tea consumers, it is essential that there are four general types of tea depending on the fermentation process of the leaves: unfermented (white and green tea), partially fermented (semifermented/oolong tea), fully fermented (black tea), and post-fermented tea (Pu-erh tea). All infusions from these tea leaves have different tastes and flavors. For consumers' taste (especially those in Western countries), green teas are enriched with dry fruits, lemon skin, or jasmine petals. But these infusions are not well characterized yet. 
White tea is produced from unopened buds, classified as silver needle or with immature leaves without green chlorophyll (silver leaves). Green tea is manufactured by drying fresh tea leaves to stop the oxidation process. Semifermented tea is partially fermented, and black teas are fully fermented teas by enzymatic oxidation process (monomeric catechins or flavan3-ols are converted into oligomeric and polymeric theaflavins and thearubigins). Pu-erh tea is a post-fermented tea (and fully fermented as black tea) produced only in Yunnan Province in China.

On the other hand, Red Lapacho herbal tea made from the bark of the plant Tabebuia impetiginosa contains compounds such as lapachol and beta-lapachone and iridoid glycosides, lignan glycosides, isocoumarin glycosides, phenylethanoid glycosides, and phenolic glycosides (Steinert et al. 1996; Warashina et al. 2004). There is a lack of information about phenolic acids in that plant.

Response surface methodology (RSM) is a mathematical and statistical technique for the analysis of fitness of empirical models and the relationships between the response and independent variables and for optimization of these factors (Bezerra et al. 2008). This method was used by Martins et al. (2013) who proposed the new method for antioxidant activity measured by ferric reducing ability of plasma (FRAP). Also a new method, artificial neural network for optimization of extraction process, was developed by Xi et al. (2013), but it was used only for the measurement of total soluble phenolics in tea infusions.

The process of catechin extraction is usually performed at $80-100{ }^{\circ} \mathrm{C}$ for several hours or maceration with the extraction solvent for days at room temperature (Rusak et al. 2008). Dry tea leaves $(1 \mathrm{~g})$ were steeped in $100 \mathrm{~mL}$ of deionized water at 95 to $100{ }^{\circ} \mathrm{C}$ for $5 \mathrm{~min}$ (Rusak et al. 2008; Unachukwu et al. 2010); Komes et al. (2010) reported that the optimal extraction conditions for all phenolic compounds (catechins, flavonols, and phenolic acids) in green tea leaves were $80^{\circ} \mathrm{C}$ in $30 \mathrm{~min}$.

Therefore, the aim of the study was to optimize the extraction process of green tea using RSM on its antioxidant activity measured using 2,2-diphenyl-1-picrylhydrazyl (DPPH) method and on its rutin and chlorogenic acid content. The optimized extraction conditions were used to analyze two flavonols, rutin and quercetin, and the most common phenolic acids and organic acids in white, pure green tea infusions, green tea infusions with fruits or jasmine petals, semifermented, black, and Pu-erh tea infusions to compare them with Red Lapacho infusion.

\section{Materials and Methods}

\section{Chemicals}

DPPH, malic acid, succinic acid, gallic acid, protocatechuic acid, chlorogenic acid, caffeic acid, $p$-coumaric acid, rutin, salicylic acid, sinapic acid, syringic acid, ferulic acid, quercetin, and $( \pm)$-6-hydroxy-2,5,7,8-tetramethylchromane2-carboxylic acid (Trolox) were purchased from SigmaAldrich Chemical Co. (Steinheim, Germany). MS grade acetonitrile was from POCH (Gliwice, Poland) and MS grade formic acid was from Sigma-Aldrich. Water was prepared by reverse osmosis in a Demiwa system from Watek (Ledec nad Sazavou, The Czech Republic), followed by double distillation from a quartz apparatus. Methanol from POCH was of analytical grade.

\section{Material and Extraction Process}

Seventeen teas including one herbal tea-three white teas, four pure green teas, five green teas with additives (lemon skin, guava and lychee flavor, dry fruits, quince fruit, jasmine petals), semifermented tea, two black teas, Pu-erh tea, and herbal tea from the bark known as Red Lapacho-were purchased at a local market and a tea shop. Two grams of leaves/ piece of bark was extracted by $100 \mathrm{~mL}$ of distilled water. The temperature of water and the time of the extraction process were based on an experimental design generated by Statistica 10.0 program from StatSoft Inc. (Tulsa, OK, USA) with the use of green tea. At the end of the defined extraction time, leaves/bark and water were separated and the infusion was cooled at room temperature. After filtration through $0.45 \mu \mathrm{m}$ polytetrafluoroethylene syringe filter from Agilent Technologies (Santa Clara, CA, USA), the solution was finally diluted to a proper volume with distilled water. The tea solution was prepared directly before the analysis (Xu et al. 2013).

\section{Experimental Design}

Determination of experimental ranges for independent variables, namely extraction time and temperature, was carried out using antioxidant activity (DPPH assay), and rutin content and chlorogenic acid content were used as determinant factors. RSM was then used to determine the optimum levels of extraction time ( $\mathrm{min})$ and temperature $\left({ }^{\circ} \mathrm{C}\right)$ using water as extraction medium on three responses, namely DPPH assay, rutin, and chlorogenic acid in the green tea extracts. The coded and uncoded independent variables, namely extraction time $\left(X_{1}\right)$ and temperature $\left(X_{2}\right)$, used in the RSM design are shown in Table 1. Ranges of extraction time and temperature with water as the extraction solvent were selected based on the habits of European consumers in preparing tea. The experiments were designed according to the central composite design (CCD) with a factorial design consisting of four factorial points, four axial points, and five central points. The adequacy of the model was determined by evaluating the lack of fit, coefficient of determination $R^{2}$, and adjusted $R^{2}$, and the Fisher test value ( $F$ value) was obtained from the analysis of variance (ANOVA) which was generated by the software. 
Table 1 Independent variables used in the RSM design

\begin{tabular}{llllllll}
\hline Factor & $\begin{array}{l}\text { Independent } \\
\text { variables }\end{array}$ & $\begin{array}{l}\text { Low } \\
\text { actual }\end{array}$ & $\begin{array}{l}\text { High } \\
\text { actual }\end{array}$ & $\begin{array}{l}\text { Low } \\
\text { coded }\end{array}$ & $\begin{array}{l}\text { High } \\
\text { coded }\end{array}$ & Mean & $\begin{array}{l}\text { Standard } \\
\text { deviation }\end{array}$ \\
\hline$X_{1}$ & Extraction time (min) & 1.00 & 20.00 & -1.00 & 1.00 & 10.50 & $\begin{array}{l}5.27 \\
X_{2}\end{array}$ \\
\hline
\end{tabular}

\section{DPPH Radical Scavenging Activity}

The ability of tea infusions to scavenge DPPH radicals was determined according to the method of Blois (1958) with slight modification. Briefly, $1.0 \mathrm{~mL}$ of a $0.5-\mathrm{mM}$ methanolic solution of DPPH was mixed with $3 \mathrm{~mL}$ of extract diluted in methanol. The mixture was then mixed and left for $30 \mathrm{~min}$ at room temperature in the dark. The absorbance of the samples was measured at $516 \mathrm{~nm}$ using a Beckman UV-VIS Spectrophotometer 7500DU (Brea, CA, USA). DPPH scavenging activity was expressed as the percentage of DPPH scavenging relative to control using the following equation:

DPPH scavenging activity $(\%)=$

$[($ Absorbance of control - Absorbance of sample $) /($ Absorbance of control $)] \times 100 \%$

Trolox was used as a standard for the calibration curve. The DPPH scavenging activity was also reported as Trolox equivalents $(\mathrm{mM})$ using the following linear equation (0.998) based on the calibration curve:

$A=2.7897 C+16.8260$

The results were expressed as millimolar of Trolox per $100 \mathrm{~mL}$ of infusion.

\section{Liquid Chromatography-Mass Spectrometry}

The UltiMate 3000 RSLC chromatographic system from Dionex (Sunnyvale, CA, USA) was used. Five-microliter samples were injected into a Gemini-NX C18 column $(100 \mathrm{~mm} \times 2.0 \mathrm{~mm}$ I.D.; $3 \mu \mathrm{m})$ from Phenomenex (Torrance, CA, USA) maintained at $35{ }^{\circ} \mathrm{C}$. The mobile phase employed in the analysis consisted of $0.1 \%$ formic acid in water and acetonitrile at a flow rate of $0.4 \mathrm{~mL} \mathrm{~min}^{-1}$. Gradient elution was performed by linearly increasing the percentage of organic modifier from 4 to $40 \%$ in $2 \mathrm{~min}$, then maintained for $8 \mathrm{~min}$ at $40 \%$, next changed to $90 \%$ in $1 \mathrm{~min}$, and maintained at $90 \%$ for 1 min. The LC column effluent was directed to the electrospray ionization source (Turbo Ion Spray).

The HPLC system was connected to the API 4000 QTRAP triple quadrupole mass spectrometer from $A B$ Sciex (Foster City, CA, USA). The Turbo Ion Spray source was operated in negative ion mode for all the analytes. The dwell time for each mass transition detected in the MS/MS multiple reaction monitoring mode was set to $100 \mathrm{~ms}$. All the compounds were detected using the following settings for the ion source and mass spectrometer: curtain gas $20 \mathrm{psi}$, nebulizer gas $45 \mathrm{psi}$, auxiliary gas $50 \mathrm{psi}$, temperature $500{ }^{\circ} \mathrm{C}$, collision gas medium, ion spray voltage $-4,500 \mathrm{~V}$, and declustering potential $-40 \mathrm{~V}$. The detected mass transitions and collision energies of each analyte are summarized in Table 2.

Calibration curve ranges of the method were tested in a wide range to ensure the linear response of analytes present in tea infusions. The matrix effect was evaluated comparing the slopes of calibration curves obtained from tea samples spiked at different concentrations with the slope of calibration curve obtained from the results gained for the standards. The quotient of the spiked sample curve slope and the standard curve slope higher than 1 indicate the existence of signal enhancement. Values lower than 1 show signal suppression. No recovery test was done as the sample preparation procedure contained only filtration and dilution steps.

\section{Statistical Analysis}

Results are expressed as mean \pm standard deviation (at least three replicates). Analysis of variance and significant differences among means and correlation analysis were performed with one-way ANOVA. The significance level was based on a confidence level of $95.0 \%$. The experimental data were analyzed using Statistica 10.0 program. 
Table 2 Names of the analytes, the $m / z$ values of their precursor and product ions, and collision energies used for fragmentation. The transitions from precursor to product ions were used for the quantitative analysis

\begin{tabular}{llll}
\hline Analyte & $\begin{array}{l}\text { Precursor ion } \\
(\mathrm{m} / \mathrm{z})\end{array}$ & $\begin{array}{l}\text { Product ion } \\
(\mathrm{m} / \mathrm{z})\end{array}$ & $\begin{array}{l}\text { Collision energy } \\
(\mathrm{V})\end{array}$ \\
\hline Rutin & 609 & 301 & -51 \\
Malic acid & 133 & 115 & -16 \\
Gallic acid & 169 & 125 & -20 \\
Chlorogenic acid & 353 & 191 & -30 \\
Succinic acid & 117 & 73 & -17 \\
Quercetin & 301 & 151 & -33 \\
Caffeic acid & 179 & 135 & -20 \\
$p$-Coumaric acid & 163 & 119 & -22 \\
Protocatechuic acid & 153 & 109 & -22 \\
Salicylic acid & 137 & 93 & -25 \\
Ferulic acid & 193 & 134 & -25 \\
Syringic acid & 197 & 182 & -18 \\
Sinapic acid & 223 & 208 & -19 \\
\hline
\end{tabular}

\section{Results and Discussion}

\section{Optimization of Extraction Process by RSM}

Tea is a product rich in many antioxidants, and apart from catechins, it also contains rutin as glycoside of flavonol and chlorogenic acid which acts as a strong antioxidant, and these are responsible for the astringent taste in tea (Scharbert et al. 2004). Therefore, it is important to extract them in proper time and temperature. The RSM was designed for these two factors and it contained 13 experiments including five replicates as center points (Table 3). The maximal predicted antioxidant activity was $81.94 \%$ and the experimental antioxidant activity was $80.84 \pm$ $0.44 \%$ with calculated optimum extraction time of $15 \mathrm{~min}$ and extraction temperature of $94{ }^{\circ} \mathrm{C}$. The maximal predicted rutin and chlorogenic acid contents for these conditions were $47.52 \pm 3.11$ and $6.66 \pm 0.58 \mu \mathrm{g} \mathrm{mL} \mathrm{m}^{-1}$, respectively. These conditions were used to determine other compounds of tea leaves and Lapacho bark infusions. Correlation analysis was carried out for rutin content against chlorogenic acid content and the result was $0.924(p<0.05)$.

The verification of model adequacy was done using lack of fit test for all the responses. It was insignificant $(p>0.05)$ so the models adequately fitted the experimental data (Table 4). The determination of coefficient $R^{2}$ and adjusted $R^{2}$ was also satisfactory to confirm the significance of the model, especially for the DPPH assay (Table 4).

The three-dimensional response surfaces were generated to show the interaction between the two-factor tests and to visualize the combined effect of factors on the responses (Supplemental Figs. 1, 2, and 3). Extraction time and temperature had significant effects on antioxidant activity measured by the DPPH test and also for rutin and chlorogenic acid contents (Supplemental Figs. 1, 2, and 3). After 15.91 min of extraction process, the antioxidant activity begins to decrease. The lower the temperature of the extraction process, the lower the antioxidant activity. These findings were similar for rutin and chlorogenic acid contents (Supplemental Figs. 2 and 3), i.e., extended time of extraction process leads to lowering of the
Table 3 Experimental design and responses of the dependent variables to extraction conditions

\begin{tabular}{|c|c|c|c|c|c|}
\hline \multirow[t]{2}{*}{ Run } & \multicolumn{2}{|c|}{ Independent variables } & \multicolumn{3}{|c|}{ Dependent variables (responses) } \\
\hline & $\begin{array}{l}X_{1} \text { : time } \\
(\mathrm{min})\end{array}$ & $\begin{array}{l}X_{2}: \text { temperature } \\
\left({ }^{\circ} \mathrm{C}\right)\end{array}$ & $\begin{array}{l}Y_{1}: \text { antioxidant } \\
\text { activity }(\%)\end{array}$ & $\begin{array}{l}Y_{2}: \text { rutin } \\
\left(\mu \mathrm{gL} \mathrm{m}^{-1}\right)\end{array}$ & $\begin{array}{l}Y_{3}: \text { chlorogenic acid } \\
\left(\mu \mathrm{gL}^{-1}\right)\end{array}$ \\
\hline 1 & 3.78 & 65.86 & 32.41 & 23.29 & 4.34 \\
\hline 2 & 3.78 & 94.15 & 64.90 & 40.43 & 6.11 \\
\hline 3 & 17.22 & 65.86 & 60.52 & 28.54 & 4.87 \\
\hline 4 & 17.22 & 94.15 & 79.30 & 39.69 & 5.67 \\
\hline 5 & 1.00 & 80.00 & 38.47 & 20.25 & 3.91 \\
\hline 6 & 20.00 & 80.00 & 75.40 & 34.60 & 5.12 \\
\hline 7 & 10.50 & 60.00 & 51.83 & 34.93 & 5.40 \\
\hline 8 & 10.50 & 100.00 & 83.11 & 44.20 & 6.73 \\
\hline 9 & 10.50 & 80.00 & 69.79 & 36.24 & 5.71 \\
\hline 10 & 10.50 & 80.00 & 68.84 & 42.23 & 6.48 \\
\hline 11 & 10.50 & 80.00 & 72.30 & 31.57 & 5.58 \\
\hline 12 & 10.50 & 80.00 & 69.54 & 36.74 & 5.77 \\
\hline 13 & 10.50 & 80.00 & 69.20 & 41.00 & 6.51 \\
\hline
\end{tabular}


Table 4 ANOVA for response surface quadratic model for antioxidant activity, rutin content, and chlorogenic acid content for green tea leaves

\begin{tabular}{|c|c|c|c|c|c|c|c|c|c|c|c|c|c|c|c|}
\hline \multirow[t]{2}{*}{ Source } & \multicolumn{5}{|c|}{$\begin{array}{l}\text { Antioxidant activity } \\
R^{2}=0.993 ; \mathrm{AdjR}^{2}=0.987\end{array}$} & \multicolumn{5}{|c|}{$\begin{array}{l}\text { Rutin content } \\
R^{2}=0.792 ; \mathrm{Adj}^{2}=0.646\end{array}$} & \multicolumn{5}{|c|}{$\begin{array}{l}\text { Chlorogenic acid content } \\
R^{2}=0.858 ; \mathrm{AdjR}^{2}=0.756\end{array}$} \\
\hline & SS & $d f$ & MS & $F$ & $p$ & SS & $d f$ & MS & $F$ & $p$ & SS & $d f$ & MS & $F$ & $p$ \\
\hline (1) Time $(L)$ & $1,333.58$ & 1 & $1,333.58$ & 710.34 & 0.00001 & 76.90 & 1 & 76.90 & 4.28 & 0.107479 & 0.41 & 1 & 0.41 & 2.01 & 0.229132 \\
\hline Time $(Q)$ & 368.02 & 1 & 368.02 & 196.03 & 0.00015 & 187.50 & 1 & 187.50 & 10.43 & 0.032007 & 4.00 & 1 & 4.00 & 19.80 & 0.011245 \\
\hline (2) Temp $(L)$ & 935.75 & 1 & 935.75 & 498.43 & 0.00002 & 214.18 & 1 & 214.18 & 11.91 & 0.026028 & 2.49 & 1 & 2.49 & 12.29 & 0.024740 \\
\hline Temp $(Q)$ & 18.36 & 1 & 18.36 & 9.78 & 0.03527 & 5.34 & 1 & 5.34 & 0.297 & 0.614674 & 0.001 & 1 & 0.001 & 0.009 & 0.926809 \\
\hline $1 L \times 2 L$ & 46.99 & 1 & 46.99 & 25.03 & 0.00747 & 8.96 & 1 & 8.96 & 0.498 & 0.519258 & 0.23 & 1 & 0.23 & 1.14 & 0.345252 \\
\hline Lack of fit & 12.33 & 3 & 4.11 & 2.19 & 0.23184 & 60.49 & 3 & 20.16 & 1.12 & 0.439694 & 0.39 & 3 & 0.13 & 0.64 & 0.627246 \\
\hline Pure error & 7.51 & 4 & 1.88 & & & 71.93 & 4 & 17.98 & & & 0.81 & 4 & 0.20 & & \\
\hline Cor total & $2,722.55$ & 12 & & & & 637.05 & 12 & & & & 8.42 & 12 & & & \\
\hline
\end{tabular}

$S S$ sum of squares, $d f$ degrees of freedom, $M S$ mean square, $F F$ value, $p p$ value

rutin and chlorogenic acid content. Extraction of these phenolics was also diminished with lowering of temperature.

Usually for the highest catechin content, water extraction procedure of tea is made in $3-5 \mathrm{~min}$ at $100{ }^{\circ} \mathrm{C}$ (Komes et al. 2010; Rusak et al. 2008; Unachukwu et al. 2010; Wu et al. 2012; Zimmermann and Gleichenhagen 2011). Our results show that for the other compounds such as rutin and chlorogenic acid, extraction time extended to $15 \mathrm{~min}$ is better. However, Vuong et al. (2011) found that the best conditions for the extraction of catechins from green tea leaves (ground to particle sizes max. $4 \mathrm{~mm}$ ) were $80{ }^{\circ} \mathrm{C}$ and $30 \mathrm{~min}$. But extraction time longer than $30 \mathrm{~min}$ may give rise to the oxidation of phenolics (Yang and Liu 2013) or even to lower catechin content than during $15 \mathrm{~min}$ of extraction (Rusak et al. 2008). Komes et al. (2010) reported that 15 min of extraction process (at $80{ }^{\circ} \mathrm{C}$ ) is the best for the extraction of total nonflavonoids and total flavonoids in loose green tea leaves. Therefore, in this context, the extraction conditions proposed in the present study are in the time frame proposed by other authors (i.e., between 3 and $30 \mathrm{~min}$ ).

These findings were also confirmed by the results of antioxidant activity measured by the DPPH assay. The same results, but for a similar test (ABTS assay), confirmed that 15 min of extraction of green tea leaves showed higher
Fig. 1 Antioxidant activity (DPPH) of infusions $(n=3)$. Mean values with different letters are significantly different in Tukey's test $(p \leq 0.01)$

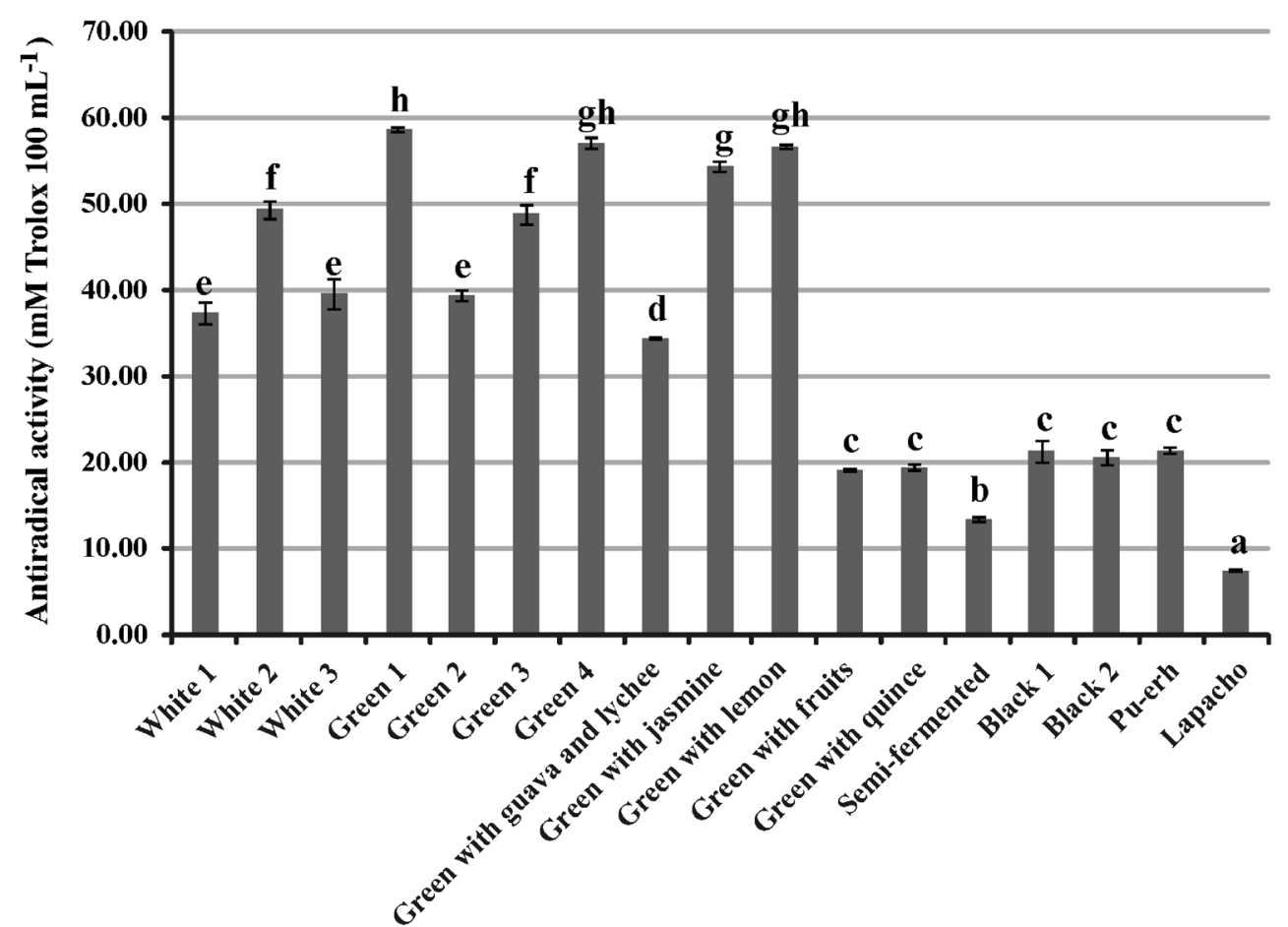



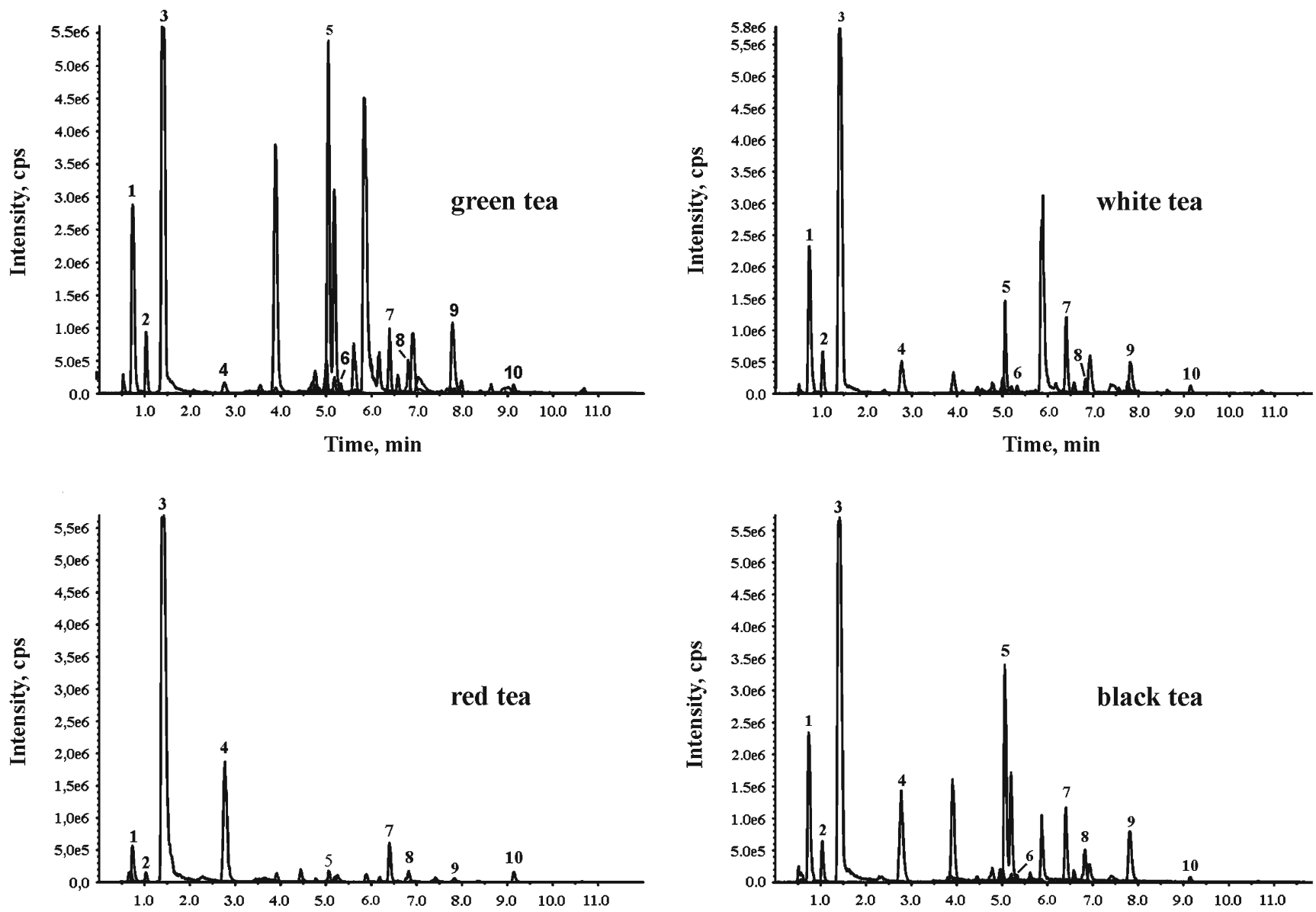

Fig. 2 Chromatograms obtained for different types of tea infusions. Peak description: 1 malic acid, 2 succinic acid, 3 gallic acid, 4 protocatechuic acid, 5 chlorogenic acid, 6 caffeic acid, $7 p$-coumaric acid, 8 rutin, 9 salicylic acid, 10 quercetin

antioxidant activity than 5 or $30 \mathrm{~min}$ (Rusak et al. 2008). Also, Komes et al. (2010) found that if the higher temperature of the extraction process (from 60 to $100{ }^{\circ} \mathrm{C}$ ) was used, the highest antioxidant activity measured in DPPH, ABTS, and FRAP assays of loose green tea leaves was obtained.

Nevertheless, it is noteworthy to stress that the extraction conditions optimized for green tea are not necessarily the optimal extraction conditions for Red Lapacho herbal infusion. This herbal infusion contains different compounds other than tea, hardly soluble in water. Identification of some constituents of Red Lapacho was published by Steinnert et al. (1995) and Warashina et al. (2004). Steinnert et al. (1995) used several different organic solvents for the extraction of the main compounds from the bark of the Lapacho tree. Among the tested solvents, methanol enabled to obtain the highest amount of extractables. Several quinone derivatives were identified. The authors also prepared extracts of Red Lapacho in boiling water because the aqueous extracts are taken by consumers. Several previously identified quinone derivatives were observed, but surprisingly, no lapachol was found which was previously said to be the active component of
Red Lapacho infusions (Steinnert et al. 1995). Warashina et al. (2004) prepared only methanol extract of Red Lapacho. Several glycosides were identified and presented in that paper (Warashina et al. 2004). However, flavonoids, phenolic acids, and simple organic acids were not previously studied in Red Lapacho infusions. For better comparison with the tea extracts, the same conditions were used in this study for all infusions.

Antioxidant Activity of Camelia sinensis and Red Lapacho Infusions

Radical scavenger activity is measured by the DPPH assay which is a rapid, simple, low cost, and widely used method to evaluate the antioxidant activity not only of compounds but also of foods, i.e., beverages (Kedare and Singh 2011; Pyrzynska and Pekal 2013; Sharma and Bhat 2009).

The antioxidant activity of two out of four pure green tea infusions was 2- or even 3-fold higher than green tea with fruits or quince (Fig. 1). Green tea infusions showed the highest antioxidant activity, and this finding was also stated by Pekal et al. (2012). Green tea with jasmine and 
green tea with lemon was significantly different than other green teas with natural additives $(p \leq 0.01)$. These findings could provide information that such additives as jasmine petals and lemon skin are excellent antioxidants, but it is also probable that cheaper teas of worse quality were used for the production of the aromatized teas. Their bitter taste caused by the presence of more polyphenols can be easily masked by fruit or artificial aroma components. These polyphenols are known strong antioxidants and could contribute to the overall antioxidant activity more than the added fruits. Therefore, the influence of fruits and aromas could be assessed only if the same tea is used for both pure and aromatized products.

White teas especially white tea no. 2 had high radical scavenger activity, almost the same as pure green tea no. 3 . These findings were previously reported by Horzic et al. (2009), Rusak et al. (2008), and Unachukwu et al. (2010). Semifermented and black teas had even 2-fold lower radical scavenger activity and this observation is not in agreement with Horzic et al. (2009) who determined the same result for white, green, semifermented, and black teas measured with the DPPH assay.

There was no significant difference between the radical scavenger activity of green tea infusion with fruits and quince, black tea, and Pu-erh tea (from 19.01 to $21.35 \mathrm{mM}$ Trolox $100 \mathrm{~mL}^{-1}$ ). Infusion made from semifermented tea leaves had the lowest activity from all teas $(p \leq 0.01)$. These findings are against the results of Kim et al. (2011), who showed that semifermented tea infusions (20-60\% of fermentation) had higher antioxidant capacity (measured by oxygen radical absorbance capacity - ORAC) than black tea infusion. This and the abovementioned differences could be explained by plant variety, leaf age and quality, and the antioxidant test. Red Lapacho infusion had the lowest activity that could be connected with the low content of phenolic compounds.

\section{Content of Phenolics and Organic Acids}

Determination of phenolics and organic acids was performed with the use of the HPLC/MS/MS technique. Linearity of the method was tested in a wide range. Satisfactory correlation was found in a relatively narrow range (Table 5). The high content of some compounds forced the dilution of the samples. On the other hand, a low amount of other analytes made it necessary to inject the undiluted samples. Thus, two runs for each sample had to be done. The matrix effect was evaluated for each analyte and satisfactory results were obtained (Table 5). The method was found to be useful for the analysis of selected phenolics and organic acids in tea samples (Fig. 2).

Teas purchased from different companies possessed varied quantities of phenolics (Table 6). Rutin was the dominant flavonol in green tea infusions and its content is lowered
Table 5 Calibration curve range, correlation coefficient, and matrix effect for the tested tea constituents

\begin{tabular}{llll}
\hline Analyte & $\begin{array}{l}\text { Calibration curve } \\
\text { range }\left(\mu \mathrm{g} \mathrm{mL}^{-1}\right)\end{array}$ & $\begin{array}{l}\text { Correlation } \\
\text { coefficient }\left(R^{2}\right)\end{array}$ & $\begin{array}{l}\text { Matrix } \\
\text { effect }\end{array}$ \\
\hline Rutin & $0.015-8.00$ & 0.999 & 0.98 \\
Malic acid & $0.006-3.00$ & 1.000 & 1.01 \\
Gallic acid & $0.006-1.50$ & 0.997 & 1.04 \\
Chlorogenic acid & $0.006-1.50$ & 0.999 & 0.89 \\
Succinic acid & $0.006-1.50$ & 0.999 & 0.98 \\
Quercetin & $0.006-1.50$ & 0.997 & 1.47 \\
Caffeic acid & $0.006-0.75$ & 0.998 & 1.00 \\
$p$-Coumaric acid & $0.002-0.50$ & 0.992 & 1.09 \\
Protocatechuic acid & $0.006-1.50$ & 0.999 & 1.13 \\
Salicylic acid & $0.006-1.50$ & 0.998 & 1.06 \\
Ferulic acid & $0.006-1.50$ & 1.000 & 0.96 \\
Syringic acid & $0.006-3.00$ & 1.000 & 1.07 \\
Sinapic acid & $0.008-2.00$ & 0.999 & 0.63 \\
\hline
\end{tabular}

during the fermentation process (with some exceptions). This observation is in agreement with Kim et al. (2011).

The quantity of phenolic acids is affected by the time of the extraction process. Gallic acid in nonfermented teas (white and green teas) was at the level from 8.51 (green 1) to $36.66 \mu \mathrm{g} \mathrm{mL}^{-1}$ (white 3), and this observation is in agreement with Kim et al. (2011). But black tea had a lower content of gallic acid than semifermented tea, and this observation is not in agreement with $\mathrm{Kim}$ et al. (2011). The total content of phenolic acids depends on extraction time. Just 5 -fold extraction time extracts a 1.5-fold higher level of total phenolic acid in green teas in comparison to the data of Horzic et al. (2009).

The major compound from phenolic acids was gallic acid and the highest level was found in Pu-erh tea infusion (Table 6). This finding was comparable with other data ( $\sim 15 \mathrm{~g} / \mathrm{kg}$ of dry weight) compared to the other types of tea (Lin et al. 1998; Wu et al. 2012). A negative correlation between rutin and gallic acid $\left(R^{2}=0.7252\right)$ for Camellia sinensis infusions (without $\mathrm{Pu}$-erh tea infusion) was observed.

On the other hand, no gallic acid was found in Red Lapacho infusion. This beverage contained mainly two phenolic acids: protocatechuic and caffeic (Table 6). Malic acid dominated in pure green tea, green tea with fruits, and Lapacho infusions. The content of this organic acid was higher in green teas with fruits.

\section{Conclusions}

RSM is a good tool to optimize the extraction process of tea leaves. Among the different types of tea, pure green tea infusion showed the highest DPPH radical scavenging activity. Some additives such as jasmine petals and lemon skin had 


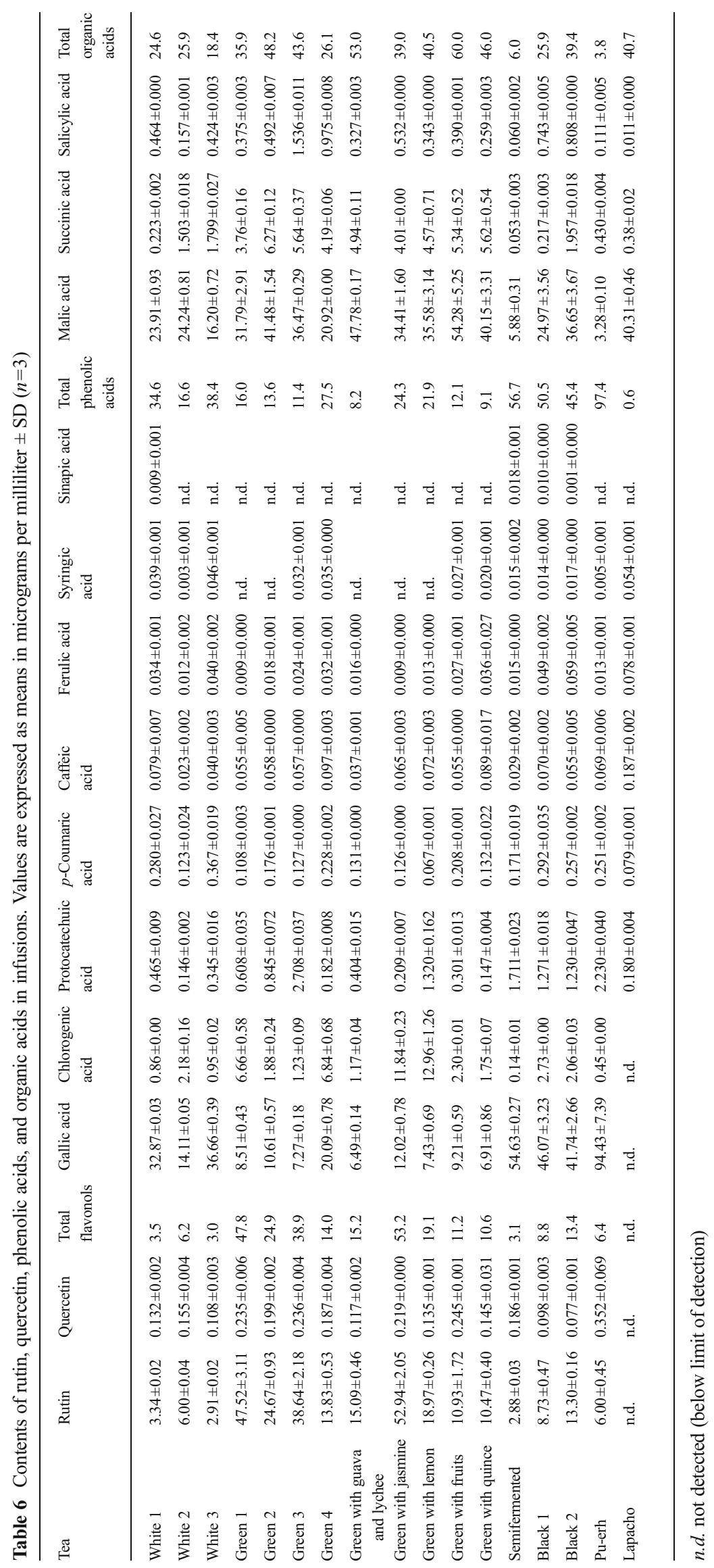


a significant influence on the antioxidant activity of green tea but dry fruits lowered it. Red Lapacho infusion had the lowest antioxidant activity which can be connected with the low content of phenolic compounds. No rutin, quercetin, gallic acid, chlorogenic acid, and sinapic acid were found in this beverage.

Acknowledgments This work was supported by grant numbers 31250/2013 DS-PB and 31-256/2013 DS-MK from the Polish Ministry of Science and Higher Education.

Conflict of Interest Magdalena Jeszka-Skowron declares that she has no conflict of interest. Agnieszka Zgoła-Grześkowiak declares that she has no conflict of interest. This article does not contain any studies with human or animal subjects.

Open Access This article is distributed under the terms of the Creative Commons Attribution License which permits any use, distribution, and reproduction in any medium, provided the original author(s) and the source are credited.

\section{References}

Bezerra MA, Santelli RE, Oliveira EP, Villar LS, Escaleira LA (2008) Response surface methodology (RSM) as a tool for optimization in analytical chemistry. Talanta 76:965-977

Blois MS (1958) Antioxidant determinations by the use of a stable free radical. Nature 26:1199-1200

Ding MY, Chen PR, Luo GA (1997) Simultaneous determination of organic acids and inorganic anions in tea by ion chromatography. $\mathrm{J}$ Chromatogr A 764:341-345

FAO (2012) Current situation and medium term outlook FAO Intergovernmental Group on tea, twentieth session of the intergovernmental group on tea, 30 January-1 February 2012, Colombo, Sri Lanka. URL http://www.fao.org/economic/est/est-commodities/tea/ tea-meetings/en/ Accessed 22.07.13.

Friedman M, Kim SY, Lee SJ, Han GP, Han JS, Lee RK, Kozukue N (2005) Distribution of catechins, theaflavins, caffeine, and theobromine in 77 teas consumed in the United States. J Food Sci 70:C550 C559

Horie H, Yamauchi Y, Kohata K (1998) Analysis of organic anions in tea infusions using capillary electrophoresis. Food Chem 817:139-144

Horzic D, Komes D, Belscak A, Ganic KK, Ivekovic D, Karlovic D (2009) The composition of polyphenols and methylxanthines in teas and herbal infusions. Food Chem 115:441-448

Kedare SB, Singh RP (2011) Genesis and development of DPPH method of antioxidant assay. J Food Sci Technol 48:412-422

Kim Y, Goodner KL, Park JD, Choi J, Talcott ST (2011) Changes in antioxidant phytochemicals and volatile composition of Camellia sinensis by oxidation during tea fermentation. Food Chem 129: $1331-1342$

Komes D, Horžić D, Belščak A, Kovačević Ganić K, Vulić I (2010) Green tea preparation and its influence on the content of bioactive compounds. Food Res Int 43:167-176

Lin YL, Juan IM, Chen YL, Liang YC, Lin JK (1996) Composition of polyphenols in fresh tea leaves and associations of their oxygen- radical-absorbing capacity with antiproliferative actions in fibroblast cells. J Agric Food Chem 44:1387-1394

Lin JK, Lin CL, Liang YC, Lin-Shiau SY, Juan IM (1998) Survey of catechins, gallic acid, and methylxanthines in green, oolong, pu'erh, and black teas. J Agric Food Chem 46:3635-3642

Lin Y, Tsai Y, Tsay J, Lin J (2003) Factors affecting the levels of tea polyphenols and caffeine in tea leaves. J Agric Food Chem 51: $1864-1873$

Martins AC, Bukman L, Vargas AM, Barizão ÉO, Moraes JC, Visentainer JV, Almeida VC (2013) The antioxidant activity of teas measured by the FRAP method adapted to the FIA system: optimising the conditions using the response surface methodology. Food Chem 138:574-580

Pekal A, Drozdz P, Pyrzynska K (2012) Comparison of the antioxidant properties of commonly consumed commercial teas. Int J Food Prop 15:1101-1109

Poon GK (1998) Analysis of catechins in tea extracts by liquid chromatography electrospray ionization mass spectrometry. J Chromatogr A 794:63-74

Pyrzynska K, Pekal A (2013) Application of free radical diphenylpicrylhydrazyl (DPPH) to estimate the antioxidant capacity of food samples. Anal Methods 5:4288-4295

Rusak G, Komes D, Likić S, Horžić D, Kovač M (2008) Phenolic content and antioxidative capacity of green and white tea extracts depending on extraction conditions and the solvent used. Food Chem 110:852858

Scharbert S, Holzmann N, Hofmann T (2004) Identification of the astringent taste compounds in black tea infusions by combining instrumental analysis and human bioresponse. J Agric Food Chem 52:3498-3508

Sharma OP, Bhat TK (2009) DPPH antioxidant assay revisited. Food Chem 113:1202-1205

Steinert J, Khalaf H, Rimpler M (1996) High-performance liquid chromatographic separation of some naturally occurring naphthoquinones and anthraquinones. J Chromatogr A 723:206209

Steinnert J, Khalaf H, Rimpler M (1995) HPLC separation and determination of naphthol[2,3-b]furan-4,9-diones and related compounds in extracts of Tabebuia avellandae (Bignoniaceae). J Chromatogr A 693:281-287

Unachukwu UJ, Ahmed S, Kavalier A, Lyles JT, Kennelly EJ (2010) White and green teas (Camellia sinensis var. sinensis): variation in phenolic, methylxanthine, and antioxidant profiles. J Food Sci 75: 541-548

Vuong QV, Golding JB, Stathopoulos CE, Nguyen MH, Roach PD (2011) Optimizing conditions for the extraction of catechins from green tea using hot water. J Sep Sci 34:3099-3106

Warashina T, Nagatani Y, Noro T (2004) Constituents from the bark of Tabebuia impetiginosa. Phytochem 65:2003-2011

Wu C, Xu H, Héritier J, Andlauer W (2012) Determination of catechins and flavonol glycosides in Chinese tea varieties. Food Chem 132: 144-149

Xi J, Xue Y, Xu Y, Shen Y (2013) Artificial neural network modeling and optimization of ultrahigh pressure extraction of green tea polyphenols. Food Chem 141:320-326

Xu YQ, Zhong XY, Yin JF, Yuan HB, Tang P, Du QZ (2013) The impact of $\mathrm{Ca}^{2+}$ combination with organic acids on green tea infusions. Food Chem 139:944-948

Yang J, Liu RH (2013) The phenolic profiles and antioxidant activity in different types of tea. Int J Food Sci Technol 48:163-171

Zimmermann BF, Gleichenhagen M (2011) The effect of ascorbic acid, citric acid and low $\mathrm{pH}$ on the extraction of green tea: how to get most out of it. Food Chem 124:1543-1548 